\title{
Research on the Amplitude Features of Stator Current for Motor with Bearing Faults
}

\author{
X.B. Wu, C.D. Qiu, G.Z. Cheng, Z.Y. Xue \\ Marine Engineering College \\ Dalian Maritime University \\ China
}

\begin{abstract}
Martin Blödt first introduced that the modulation mode between fundamental frequency of rotor vibration, which is caused by bearing faults, and fundamental frequency of stator current is phase modulation. This paper accomplished the theoretical derivation about the impact of bearing fault on stator current based on torque vibration harmonics, and gave the amplitude expression of stator current fault-related frequencies. The bearing fault simulation device which could simulate singlepoint defect was established. The effect of torque vibration harmonics on stator current amplitude was verified by simulation and experimental research. The obtained results showed that the amplitude features of stator current are not only related to the fault severity but also related to the size of the fault zone.
\end{abstract}

Keywords-motor; bearing; fault; phase modulation; amplitude

\section{INTRODUCTION}

Three-phase induction motors play an important role in various fields of daily lives and industrial productions because of their low cost and high robustness. However, bearing faults in motors are common [1, 2]. It is of great significance to monitor bearing condition. The conventional bearing fault detection is vibration-based method. However, the vibration detection system is highly complicated, not to mention its high initial investment and post-maintenance costs $[3,4]$. Due to the advantages that the current is often available or not very expensive to measure, the method based on stator current has become one of the main methods of detecting bearing faults nowadays [3, 5].

In this paper, considering the harmonics of torque vibration caused by motor bearing faults, the relationship between the torque vibration and the stator current is theoretically derived. Bearing fault simulation device is designed to study the amplitude features of stator current affected by the vibration characteristic.

\section{AMPLITUDE FEATURES OF STATOR CURRENT BASED ON PHASE MODULATION}

When a ball passes through a defect, an impact occurs, which will induce vibration and impede the rotation of the bearing [6]. Therefore, square wave pulse torque vibration whose frequency is related to the location of the fault will generate. The fundamental frequencies of vibration are given by [7]:

$$
\begin{aligned}
f_{o} & =0.5 N f_{r}\left[1-\left(D_{b} \cos \alpha\right) / D_{c}\right] \\
f_{i} & =0.5 N f_{r}\left[1+\left(D_{b} \cos \alpha\right) / D_{c}\right]
\end{aligned}
$$

$$
\begin{aligned}
& f_{b}=D_{c} f_{r}\left[1-\left(D_{b}^{2} \cos ^{2} \alpha\right) / D_{c}^{2}\right] / D_{b} \\
& f_{\text {cage }}=0.5 f_{r}\left[1-\left(D_{b} \cos \alpha\right) / D_{c}\right]
\end{aligned}
$$

Where $f_{o}$ denotes outer raceway vibration frequency, $f_{i}$ denotes inner raceway vibration frequency, $f_{b}$ denotes ball vibration frequency and $f_{\text {cage }}$ denotes cage vibration frequency. The mechanical rotor frequency is denoted $f_{r}, N$ is the number of balls, the diameter of the ball is $D_{b}$, the pitch diameter is $D_{c}$, and $\alpha$ is the contact angle between the ball and the raceway.

The torque vibration can be expanded in accordance with the Fourier series. Considering the harmonics, the load torque is shown in (5).

$$
\mathrm{T}_{l}(t)=\mathrm{T}_{0}+\sum_{n=1}^{\infty} \mathrm{T}_{n} \cos \left(n \omega_{c} t\right)
$$

Where $\mathrm{T}_{l}$ is the load torque, $\mathrm{T}_{0}$ is the constant part of the load torque, $\mathrm{T}_{n}$ is the peak amplitude of torque caused by bearing faults, and $\omega_{c}$ is fault-related fundamental angular frequency of vibration.

The angular frequency of rotor can be obtained on the basis of mechanical equation. Then the mechanical position of the rotor can be obtained by integrating it. In the stator reference coordinate, the rotor magnetomotive force is given by

$$
\begin{aligned}
F_{r}{ }^{S}(\theta, t) & =F_{r} \cos \left(p \theta-\omega_{s} t-\sum_{n=1}^{\infty} p \frac{\mathrm{T}_{n} \cos \left(n \omega_{c} t\right)}{J\left(n \omega_{c}\right)^{2}}\right) \\
& =F_{r} \cos \left(p \theta-\omega_{s} t-\sum_{n=1}^{\infty} \beta_{n} \cos \left(n \omega_{c} t\right)\right)
\end{aligned}
$$

Where $\theta$ is the mechanical angle in the stator reference coordinate, $\beta_{n}=p \mathrm{~T}_{n} /\left[J\left(n \omega_{c}\right)^{2}\right]$ is the amplitude of the angle variation. Because the effect of bearing fault on the air gap is not considered, the air gap can be regarded as unchanged. Then the air gap permeance $\Lambda$ remains unchanged. The stator magnetomotive force is also assumed to be changeless, so just consider the effect of rotor magnetomotive force on the stator current. The rotor flux density is given as below:

$$
B_{r}(\theta, t)=F_{r} \Lambda \cos \left(p \theta-\omega_{s} t-\sum_{n=1}^{\infty} \beta_{n} \cos \left(n \omega_{c} t\right)\right)
$$

The magnetic flux $\Phi_{r}(t)$ can be obtained by integrating the flux density. According to the stator voltage equation $V(t)=R_{s} I(t)+d \Phi_{r}(t) / d t$, the stator current affected by the rotor magnetomotive force can be expressed as:

$$
\begin{aligned}
I(t)= & I_{1} \sin \left(\omega_{s} t+\sum_{n=1}^{\infty} \beta_{n} \cos \left(n \omega_{c} t\right)\right) \\
& +\sum_{n=1}^{\infty} I_{2} \cos \left(\omega_{s} t+\sum_{n=1}^{\infty} \beta_{n} \cos \left(n \omega_{c} t\right)-n \omega_{c} t\right) \\
& -\sum_{n=1}^{\infty} I_{2} \cos \left(\omega_{s} t+\sum_{n=1}^{\infty} \beta_{n} \cos \left(n \omega_{c} t\right)+n \omega_{c} t\right)
\end{aligned}
$$

Where $I_{2}=\left|I_{1} \beta_{n} n \omega_{c} / 2 \omega_{s}\right|$, the amplitude of $I_{1}$ is much larger than that of $I_{2}$, so the latter one can be ignored. 
According to Bessel function of the first kind, $I(t)$ becomes

$$
\begin{aligned}
I(t) & =I_{1} \sin \left(\omega_{s} t+\sum_{n=1}^{\infty} \beta_{n} \cos \left(n \omega_{c} t\right)\right) \\
& =I_{1} \operatorname{Im}\left[e^{j \omega_{s} t} e^{j \sum_{n=1}^{\infty} \beta_{n} \cos \left(n \omega_{c} t\right)}\right] \\
& =I_{1} \operatorname{Im}\left[e^{j \omega_{s} t} \prod_{n=1}^{\infty} \sum_{m=-\infty}^{\infty} J_{m}\left(\beta_{n}\right) e^{j m n \omega_{c} t}\right]
\end{aligned}
$$

Only considering the fundamental frequency of vibration, the second harmonic of vibration and the third harmonic of vibration (other order vibration frequencies follow the same rule), the equation (9) can be expanded as (10).

$$
\begin{aligned}
I(t) & =I_{1} \operatorname{Im}\left[e^{j \omega_{s} t} \sum_{a=-\infty}^{\infty} J_{a}\left(\beta_{1}\right) e^{j a \omega_{c} t} \sum_{b=-\infty}^{\infty} J_{b}\left(\beta_{2}\right) e^{j 2 b \omega_{c} t} \sum_{c=-\infty}^{\infty} J_{c}\left(\beta_{3}\right) e^{j 3 c \omega_{c} t}\right] \\
& =I_{1} \operatorname{Im}\left[\sum_{a, b, c=-\infty}^{\infty} J_{a}\left(\beta_{1}\right) J_{b}\left(\beta_{2}\right) J_{c}\left(\beta_{3}\right) e^{j\left(\omega_{s} t+a \omega_{c} t+2 b \omega_{c} t+3 c \omega_{c} t\right)}\right] \\
& =I_{1} \sum_{a, b, c=-\infty}^{\infty} J_{a}\left(\beta_{1}\right) J_{b}\left(\beta_{2}\right) J_{c}\left(\beta_{3}\right) \sin \left(\omega_{s} t+(a+2 b+3 c) \omega_{c} t\right)
\end{aligned}
$$

Where $\beta_{1}$ is the modulation index of vibration fundamental frequency, $\beta_{2}$ is the modulation index of second harmonic, and $\beta_{3}$ is the modulation index of third harmonic.

Taking into account the vibration fundamental frequency, the second harmonic and the third harmonic, the amplitudes of stator current fault-related frequencies are shown in the table 1.

TABLE I. AMPLITUDES OF STATOR CURRENT FAULT-RELATED FREQUENCIES.

\begin{tabular}{|c|c|}
\hline frequency & amplitude \\
\hline$f_{s}+f_{c}$ & $I_{1} J_{1}\left(\beta_{1}\right) J_{0}\left(\beta_{2}\right) J_{0}\left(\beta_{3}\right)-I_{1} J_{1}\left(\beta_{1}\right) J_{1}\left(\beta_{2}\right) J_{0}\left(\beta_{3}\right)-I_{1} J_{0}\left(\beta_{1}\right) J_{1}\left(\beta_{2}\right) J_{1}\left(\beta_{3}\right)+\ldots$ \\
\hline$f_{s}-f_{c}$ & $I_{1} J_{1}\left(\beta_{1}\right) J_{0}\left(\beta_{2}\right) J_{0}\left(\beta_{3}\right)+I_{1} J_{1}\left(\beta_{1}\right) J_{1}\left(\beta_{2}\right) J_{0}\left(\beta_{3}\right)+I_{1} J_{0}\left(\beta_{1}\right) J_{1}\left(\beta_{2}\right) J_{1}\left(\beta_{3}\right)+\ldots$ \\
\hline$f_{s}+2 f_{c}$ & $I_{1} J_{0}\left(\beta_{1}\right) J_{1}\left(\beta_{2}\right) J_{0}\left(\beta_{3}\right)+I_{1} J_{2}\left(\beta_{1}\right) J_{0}\left(\beta_{2}\right) J_{0}\left(\beta_{3}\right)-I_{1} J_{1}\left(\beta_{1}\right) J_{0}\left(\beta_{2}\right) J_{1}\left(\beta_{3}\right)+\ldots$ \\
\hline$f_{s}-2 f_{c}$ & $I_{1} J_{0}\left(\beta_{1}\right) J_{1}\left(\beta_{2}\right) J_{0}\left(\beta_{3}\right)-I_{1} J_{2}\left(\beta_{1}\right) J_{0}\left(\beta_{2}\right) J_{0}\left(\beta_{3}\right)+I_{1} J_{1}\left(\beta_{1}\right) J_{0}\left(\beta_{2}\right) J_{1}\left(\beta_{3}\right)+\ldots$ \\
\hline$f_{s}+3 f_{c}$ & $I_{1} J_{0}\left(\beta_{1}\right) J_{0}\left(\beta_{2}\right) J_{1}\left(\beta_{3}\right)+I_{1} J_{1}\left(\beta_{1}\right) J_{1}\left(\beta_{2}\right) J_{0}\left(\beta_{3}\right)+I_{1} J_{3}\left(\beta_{1}\right) J_{0}\left(\beta_{2}\right) J_{0}\left(\beta_{3}\right)+\ldots$ \\
\hline$f_{s}-3 f_{c}$ & $I_{1} J_{0}\left(\beta_{1}\right) J_{0}\left(\beta_{2}\right) J_{1}\left(\beta_{3}\right)-I_{1} J_{1}\left(\beta_{1}\right) J_{1}\left(\beta_{2}\right) J_{0}\left(\beta_{3}\right)+I_{1} J_{3}\left(\beta_{1}\right) J_{0}\left(\beta_{2}\right) J_{0}\left(\beta_{3}\right)+\ldots$ \\
\hline
\end{tabular}

\section{RESEARCH ON THE AMPLITUDE FEATURES OF STATOR} CURRENT

A. Simulation Research on the Amplitude Features of Stator Current

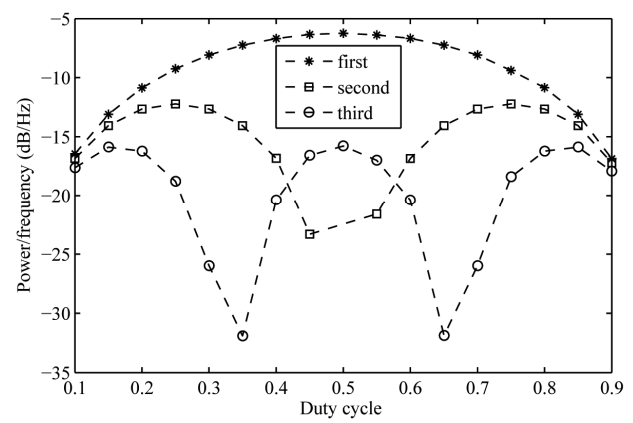

FIGURE I. TORQUE HARMONIC SPECTRUM FOR DIFFERENT DUTY CYCLES.

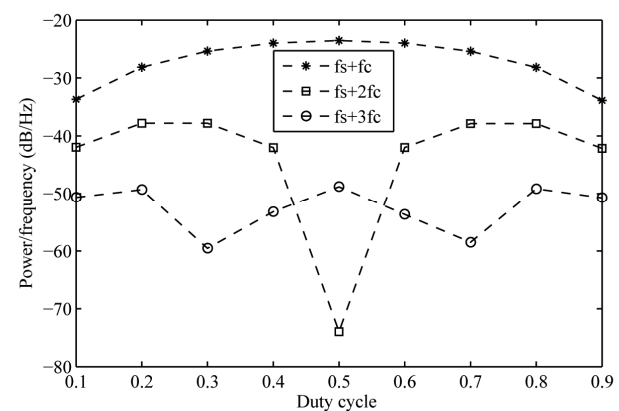

FIGURE II. STATOR CURRENT SPECTRUM FOR DIFFERENT DUTY CYCLES AT $F_{S}+K F_{C}$.

To illustrate the effect of torque vibration fundamental frequency and harmonics on the stator current spectrum, the conditions that the constant part of torque is $7 \mathrm{~N} . \mathrm{m}$ and the variation part is $2 \mathrm{~N} . \mathrm{m}$ with different duty cycles and frequency $15 \mathrm{~Hz}$ are simulated in MATLAB/SIMULINK. And the torque spectrum of the first three harmonics is shown in fig. 1. The stator current spectrum of the fault-related frequencies $f_{s}+k f_{c}$ $(k=1,2,3)$ is shown in fig. 2 .

It can be seen that the amplitude features of stator current fault-related frequencies are almost the same as the curves of torque vibration harmonics.

[8] has proposed the idea that the modulation index $\beta$ is related to the fault severity with a small value, generally less than 0.1 . On the basis of [9]

$$
J_{n}(\beta) \approx \frac{\beta^{n}}{2^{n} n !}(n \geq 0)
$$

It can be seen that the amplitude of $J_{0}(\beta)$ is the largest, which closes to 1 . The relationship between the amplitude of $J_{1}(\beta)$ and the modulation index $\beta$ is approximately linear. $J_{1}(\beta)$ approximately equals to $0.5 \beta$. The amplitudes of $J_{2}(\beta)$ and other higher orders are getting smaller and tend to be zero. Then the amplitudes of stator current fault-related characteristic frequencies given in table 1 can simplify to $0.5 I_{1} \beta_{\mathrm{k}}(\mathrm{k}=1,2,3)$. Therefore, it can be concluded that the amplitudes of the stator current fault-related characteristic frequencies depend on the same order frequency of torque vibration.

\section{B. Experimental Research on the Amplitude Features of Stator current based on Simulated Torque Vibration Signal}

Reference [10] shows that the energy of fault-related characteristic frequencies is generally much less than that of noise. Considering that the amplitude of torque vibration induced by motor bearing fault is small, the bearing fault simulation device is designed under the laboratory condition to enhance the vibration characteristic, which is highly conducive to fault identification. Its circuit principle diagram is shown in fig. 3. 


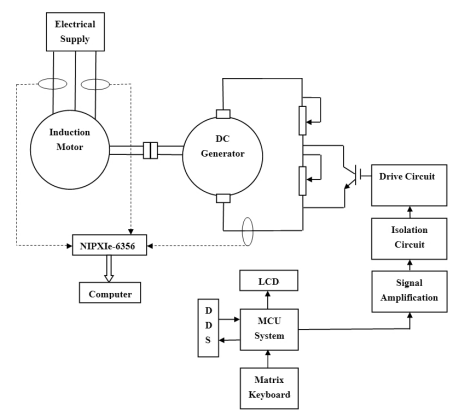

FIGURE III. MOTOR BEARING FAULT SIMULATION DEVICE.

The parameters of the three-phase induction motor are as follows: rated power $2.2 \mathrm{~kW}$; rated voltage $380 \mathrm{~V}$; frequency $50 \mathrm{~Hz}$; rated current $5.03 \mathrm{~A}$; rated speed $1430 \mathrm{r} / \mathrm{min}$; pole pairs 2 ; bearing type 6206 . The trigger frequency and duty cycle of IGBT can be adjusted. The resistance value of the sliding rheostat which is connected in parallel with the IGBT is 21.4 $\Omega$ and the other one is $43.2 \Omega$. Induction motor stator current and DC generator load current are acquired by LEM IT60-S Hall current sensors.

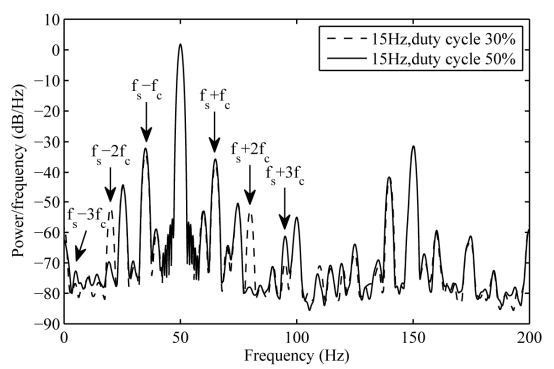

FIGURE IV. STATOR CURRENT SPECTRUM WITH THE TRIGGER FREQUENCY $15 \mathrm{H}_{\mathrm{Z}}$ AND DUTY CYCLE 30\%, 50\%.

The duty cycle of the torque vibration is set as $30 \%$ and $50 \%$, and the stator current spectrum is shown in fig. 4 .

As can be seen, compared with the situation that the duty cycle is $30 \%$, the spectrum values of the first pair and the third pair fault-related characteristic frequencies are larger when the duty cycle is $50 \%$. However, the second pair is far less than the condition that the duty cycle is $30 \%$. It accords with the rules of corresponding order vibration frequency spectrum shown in fig. 1.

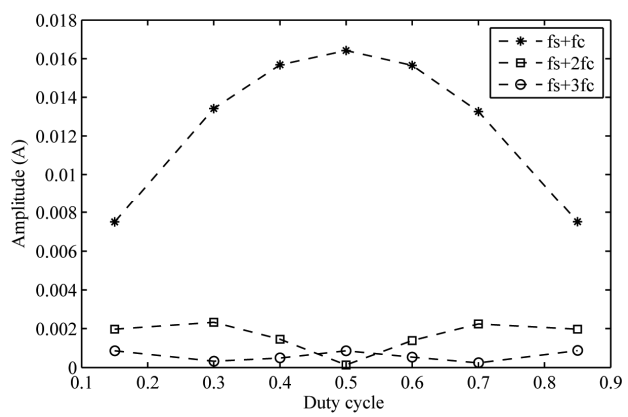

FIGURE V. STATOR CURRENT AMPLITUDE RESPONSE FOR DIFFERENT DUTY CYCLES AT $F_{S} \pm K F_{C}$.
The stator current is also acquired when the duty cycles are $15 \%, 40 \%, 60 \%, 70 \%, 85 \%$. The stator current spectrum of all above signals at the fault-related frequencies $f_{s}+k f_{c}$ is nearly the same as fig. 2. The amplitude response is shown in fig. 5 . In summary, the amplitudes of stator current fault-related characteristic frequencies depend on the amplitudes of torque vibration fundamental frequency and harmonics.

\section{CONCLUSION}

In this paper, considering the torque vibration harmonics, the relationship between bearing fault and stator current was theoretically derived. The amplitude curves of stator current fault-related frequencies were obtained based on the simulation and experimental research. And the effect of torque vibration harmonics on the amplitude of stator current faultrelated frequencies is validated. Based on the obtained results, it can be concluded that the amplitude features of stator current fault-related frequencies are not only related to the fault severity but also related to the size of the fault zone.

\section{ACKNOWLEDGEMENTS}

This research is supported by the National Natural Science Foundation of China (51279020). The support is greatly appreciated.

\section{REFERENCES}

[1] Bonnett, A.H. \& Yung, C., Increased efficiency versus increased reliability. IEEE Industry Applications Magazine, 14(1), pp. 29-36, 2008.

[2] Bouchikhi, E.H.E., Choqueuse, V. \& Benbouzid, M.E.H., Current frequency spectral subtraction and its contribution to induction machines' bearings condition monitoring. IEEE Transactions on Energy Conversion, 28(1), pp. 135-144, 2013.

[3] Blödt, M., Granjon, P., Raison, B. \& Rostaing G., Models for bearing damage detection in induction motors using stator current monitoring. IEEE Transactions on Industrial Electronics, 55(4), pp. 1813-1822, 2008

[4] Zoubek, H., Villwock, S. \& Pacas, M., Frequency response analysis for rolling-bearing damage diagnosis. IEEE Transactions on Industrial Electronics, 55(12), pp. 4270-4276, 2008.

[5] Zhou, W., Lu, B., Habetler, T.G. \& Harley R.G., Incipient bearing fault detection via motor stator current noise cancellation using wiener filter. IEEE Transactions on Industry Applications, 45(4), pp. 1309-1317, 2009

[6] Trajin, B., Regnier, J. \& Faucher, J., Comparison between vibration and stator current analysis for the detection of bearing faults in asynchronous drives. IET Electric Power Applications, 4(2), pp. 90-100, 2010.

[7] Immovilli, F., Bellini, A., Rubini, R. \& Tassoni, C., Diagnosis of bearing faults in induction machines by vibration or current signals: A critical comparison. IEEE Transactions on Industry Applications, 46(4), pp. 1350-1359, 2010.

[8] Blödt, M., Chabert, M., Regnier, J. \& Faucher J., Maximum-likelihood parameter estimation for current-based mechanical fault detection in induction motors", IEEE International Conference on Acoustics, Speech and Signal Processing, Toulouse, 2006.

[9] Wu, X.B., Qiu, C.D., Xia, M., Cheng, G.Z. \& Xue, Z.Y., Research on the current feature of induction motor bearing fault based on phase modulation. Fifth International Conference on Intelligent Control and Information Processing, Dalian, 2014.

[10] Akin, B., Orguner, U., Toliyat, H.A. \& Rayner, M., Phase-sensitive detection of motor fault signatures in the presence of noise. IEEE Transactions on Industrial Electronics, 55(6), pp. 2539-2550, 2008. 